\title{
O USUÁRIO E O AMBIENTE VIRTUAL: REVISÃO DE LITERATURA DE DISSERTAÇÕES E TESES SOBRE REDES SOCIAIS ENTRE 2008 E 2014
}

\author{
Rogerio do Amaral \\ Universidade do Oeste Paulista - UNOESTE, Presidente Prudente, SP. E-mail: professorrgamaral@gmail.com.
}

\begin{abstract}
RESUMO
Com o advento das redes sociais, a relação interpessoal foi impactada de forma abrangente, assim como profundas mudanças originaram-se da possibilidade de se relacionar com outro sujeito por meio da internet. Nesse contexto, esse artigo tem o objetivo de apresentar um grupo de trabalhos de pós-graduação de mestrado e doutorado que já se debruçaram sobre essa nova realidade de comunicação, a interação virtual. Para tanto, procedeu-se uma revisão de literatura entre dissertações e teses realizadas no período de 2008 a 2014, cuja temática tinha a pretensão de entender como o usuário transita nesse espaço. Os resultados dessa revisão de literatura foram empregados na construção da tese de doutorado intitulada "Exposição privada nas redes sociais: uma análise sobre o Facebook na sociedade contemporânea".
\end{abstract}

Palavras-chave: revisão de literatura, redes sociais, internet.

\section{THE USER AND THE VIRTUAL ENVIRONMENT: REVIEW OF LITERATURE OF DISSERTATIONS AND THESES ON SOCIAL NETWORKS BETWEEN 2008 AND 2014}

\begin{abstract}
With the advent of social networks, the interpersonal relationship was comprehensively impacted, as well as profound changes originated from the possibility of relating to another person through the internet. In this context, this article aims to present a group of master's and doctoral postgraduate studies that have already focused on this new reality of communication, virtual interaction. For that, a literature review was carried out between dissertations and theses conducted in the period from 2008 to 2014, whose thematic one had the pretension to understand how the user transits in that space. The results of this literature review were used in the construction of the doctoral thesis titled "Private exhibition in social networks: an analysis on Facebook in contemporary society".
\end{abstract}

Keywords: Literature review, social networks, internet. 


\section{INTRODUÇÃO}

A Rede Mundial de Computadores, Internet, nasce como um programa militar de defesa e se consolida como um meio de comunicação, cuja capacidade técnica permite a junção de todos os outros meios de comunicação existentes. Suas características também permitiram um avanço muito rápido, o que possibilitou a essa rede assumir um importante papel na sociedade contemporânea. Mobilidade e agilidade são as principais virtudes desse mecanismo que impacta os usuários espalhados por todos os cantos do planeta. Sorj (2003) afirma que a internet se refere a uma nova tecnologia da comunicação que se agregou a uma lista de instrumentos de transmissão de voz e imagem que modificaram a comunicação na sociedade contemporânea, como o telégrafo, o telefone, o telex, o rádio, a televisão e o fax. Essa nova tecnologia da comunicação, ao permitir a comunicação instantânea entre computadores, disponibilizou cada vez mais informação a um custo cada vez menor.

Quanto ao funcionamento técnico, Ward (2006) conceitua a internet como uma infraestrutura que possibilita aos computadores estabelecer comunicação entre si por todo o planeta, enquanto Castells (2001) a vê como um produto que ultrapassa a barreira tecnológica e se insere também na área da comunicação e no papel de meio de comunicação permitindo que a troca de informação seja realizada de muitos para muitos, em amplitude global. Trata-se de um sistema que rompe as características de tempo e espaço de todos os demais meios de comunicação anteriores a ele.

No que tange à sua função social, Recuero (2009) afirma que a internet possibilitou a expressão e a sociabilização através das ferramentas de comunicação mediada pelo computador (CMC). Tais ferramentas permitiram aos atores construir-se, interagir e comunicar-se com outros atores, deixando, na rede de computadores, rastros que consentem o reconhecimento dos padrões de suas conexões e a visualização de suas redes sociais através desses rastros. Na Internet, as relações tornam-se variadas, com trocas de diferentes tipos de informação em diferentes sistemas. Esse espaço também deu origem aos laços sociais mantidos a distância.

Tais laços sociais se tornaram mais eficazes com o advento das redes sociais, que são páginas virtuais de relacionamento que possibilitaram uma interação social rápida e abrangente, jamais vista em qualquer outro momento da história. Para Boyd e Ellison (2007), os sites de redes sociais se referem a locais na internet que permitem ao usuário construir um perfil individual público orientado pela política do sistema, assim como a criação de uma lista de usuários com os quais poderão estabelecer relações virtuais por meio do cruzamento de dados produzidos em suas páginas pessoais.

Dessa forma, ao mencionarmos o termo rede social, fazemos referência a um conjunto de pessoas, organizações ou entidades sociais conectadas por relacionamentos pessoais, motivados pela amizade (estende-se para o ambiente virtual as relações do mundo físico), relações de trabalho ou compartilhamento de informações. Para Lévy (2003), essas redes sociais na internet constituíram comunidades virtuais que produziram uma nova maneira de fazer sociedade. Isso não significa a origem de uma subsociedade, porém tem-se um novo filtro para a sociedade já existente. Implica dizer então que o ambiente virtual possibilitou a expansão do social. Portanto, a relação entre virtual e social rompeu com a barreira física do território, assim como reconstruiu a ideia de espaço-tempo, colocando em destaque a quantidade de interações interpessoais realizadas e não mais o conteúdo que uma interação pode produzir.

Independente da forma como se estabelece a conexão, redes sociais envolvem um conjunto de atores que mantêm ligações entre si. A abordagem de redes sociais deve considerar que esse espaço é um elemento em constante mutação no tempo, pois não existem redes paradas no tempo e no espaço, elas são dinâmicas e sempre se transformam, principalmente, por causa das interações ocorridas em seu interior, fato que corrobora com o papel do ator social na construção da forma de funcionamento da rede (RECUERO, 2009). 
Diante desse contexto, esse artigo tem o objetivo de apresentar a revisão de literatura realizada na produção da tese de doutorado "Exposição privada nas redes sociais: uma análise sobre o Facebook na sociedade contemporânea", defendida por este pesquisador em junho de 2016, referente a pesquisas de mestrado e doutorado que abordassem o tema internet, redes sociais e Facebook. Quando da pesquisa das teses e dissertações já produzidas, em janeiro de 2015, a proposta era analisar trabalhos desenvolvidos nos últimos dez anos, ou seja, pesquisas concluídas a partir de 2005 , porém, depois de levantados os materiais, encontrou-se estudos produzidos apenas entre 2008 e 2014.

\section{METODOLOGIA}

O procedimento metodológico para a realização desse trabalho consistiu em uma revisão de literatura na plataforma Capes utilizando-se os descritores Internet, Redes Sociais e Facebook. A pesquisa desses descritores se deu de três maneiras distintas. Na primeira etapa levantaram-se teses e dissertações por meio de descritor isolado, ou seja, no campo de busca digitava-se "Internet", "Redes sociais" e "Facebook". Na sequência, a procura procedeu a pesquisa por pares dos descritores: "Internet + Redes sociais", "Internet + Facebook" e "Redes Sociais + Facebook". Por fim, a pesquisa buscou textos a partir da digitação dos três descritores em conjunto "Internet + Redes sociais + Facebook".

Diante das opções fornecidas pelo sistema, o pesquisador procedeu à leitura dos resumos, visando estabelecer uma relação entre os trabalhos e sua tese de doutorado que consistiu em uma abordagem sobre o Facebook na contemporaneidade, assim como compreender as principais formas empregadas pelos usuários para participar desse ambiente virtual. Ao final desse levantamento, foram selecionadas dez teses de doutorado e onze dissertações de mestrado, cuja temática se aproximavam do estudo que se pretendia desenvolver na tese. Os trabalhos selecionados para essa análise serão apresentados nesse artigo de acordo com o agrupamento por temáticas de investigação.

\section{RESULTADOS}

A primeira parte dessa revisão apresenta 11 trabalhos cujo estudo norteou-se pela observação de como o usuário constrói sua identidade no espaço virtual das redes sociais. A investigação desenvolvida teve a intenção de compreender como se dá a participação desses sujeitos nas redes virtuais, visando à discussão sobre a existência de um comportamento padrão ou a predominância de uma personalidade livre, o que daria ao espaço uma característica multifacetada devido à ocorrência desse comportamento distinto por parte de cada membro.

Larissa Fabricio Zanin defendeu a tese "Fotografia e interação: modos de apresentação do adolescente e da escola no ciberespaço", no PPGE da Universidade Federal do Espírito Santo, no ano de 2012. Essa pesquisa teve a intenção de abordar os sentidos presentes nas fotografias de adolescentes nos álbuns do Orkut e também a maneira como a escola é descrita pelos adolescentes tanto nos álbuns como na própria rede social. A pesquisa considerou os álbuns do Orkut como um espaço portador de significados. O propósito do trabalho consistiu em refletir o poder da imagem fotográfica e seu caráter de veridicção, assim como verificar a construção da identidade/alteridade através de práticas sociais vividas no ciberespaço.

Em 2012, na área de Educação da Universidade do Estado do Rio de Janeiro, Robson Fonseca Simões defendeu a tese "Escritas à deriva: testemunhos efêmeros sobre os tempos da escola nas comunidades do Orkut", com o objetivo de dar visibilidade a escritas autobiográficas virtuais sobre a vida escolar, empregando tais relatos como fonte para a história da Educação. A pesquisa foi norteada por questionamentos que visavam a identificar como os relatos das histórias escolares eram realizados e quais eram os mais frequentes. 
André Alexandre Padilha Leitão defendeu a tese "Formas e funções da autoria na internet: uma prática discursiva", em 2011, na área de Letras da Universidade Federal de Pernambuco. 0 objetivo consistiu na investigação de formas e funções da autoria na Internet, principalmente, nos sites de redes sociais. A internet alterou a noção de autoria no ambiente online, pois nesse espaço há dispensa de um mediador para a publicação de textos, vídeos, fotografias, música, ou qualquer outro gênero responsável pela materialização discursiva.

Matthias Ammann defendeu em 2011, na área de Educação da Universidade de Brasília a dissertação "Facebook, eu curto: uma análise mimética das redes sociais digitais." O objetivo consistiu em redescobrir as relações miméticas que se apresentam por trás do ato de curtir no Facebook. O novo sujeito que emerge com o surgimento das novas tecnologias e o contexto em que ele atua apresenta como consenso o trânsito por um mundo marcado pela velocidade dos desdobramentos, centralidade da informação e da comunicação em amplitude global e a tecnologia e sua arquitetura em rede, especialmente, através da internet e as facilidades para que o sujeito aja no ambiente virtual. Assim, o ambiente de informação veloz da contemporaneidade provoca mais impacto que os ambientes anteriores, pois na contemporaneidade é muito mais fácil, a partir de um simples clique, mandar um e-mail de um lado para o outro do planeta.

João Vitor Rodrigues Gonçalves defendeu a dissertação na área da Comunicação Social intitulada "Gramática da Amizade: um estudo sobre Comunicação e a construção das emoções nas redes sociais online", produzida no ano de 2012, na Pontifícia Universidade Católica do Rio de Janeiro. Com a internet, a amizade passa a receber o suporte de ferramentas de comunicação mediadas pelo computador, fator que permitiu aos amigos manter contato com mais frequência para trocar mensagens, compartilhar arquivos ou bater papo. Dentre essas ferramentas, se destaca o Facebook, site de rede social que permite a conexão entre amigos. Nesse espaço social de interação, os amigos reproduzem códigos da relação existentes fora da rede social online. Diante desse contexto, a pesquisa se propõe a compreender quais são esses códigos e como eles são reproduzidos no online, como no offline.

Joyce Galdino Gomes defendeu a dissertação "Mídias sociais, adolescentes e cidadania: espaço de representações e de educação para a mídia", no ano de 2014. A pesquisa foi realizada na área de Educação, na Unesp de Presidente Prudente. Esse trabalho se desenvolveu em torno do objetivo de identificar e analisar a representação social de adolescentes do ensino médio, sobre a função da mídia social (Facebook) na construção do conceito de cidadania. A pretensão do estudo foi contribuir com a compreensão do recente fenômeno das mídias sociais, tão presente na vida dos adolescentes, assim como investigar as interferências sociais dessas mídias.

Fernanda Perroni Claro defendeu em 2012 a dissertação "Meninas, espelhos e fotografias: o edulcore da aparência na internet". Esse trabalho foi desenvolvido na área de Artes e Educação, na Universidade Estadual Paulista, Campus de São Paulo. Desde a invenção da fotografia, o retrato fotográfico sempre funcionou como instrumento de apresentação social. Na modernidade, a apresentação social se dá por meio da fotografia digital e sua livre circulação nas páginas de redes sociais através dos perfis de seus usuários.

Fabíola da Silva Cunha defendeu a dissertação de mestrado em Educação, pela Unesp de Rio Claro, no ano de 2012. Seu trabalho foi intitulado "As marcas de uma escola apontadas pelos membros de uma comunidade no Orkut", a partir do interesse em estudar como se dá a construção da narrativa produzida por um dado membro de rede social sobre si mesmo e o significado que esse mesmo membro atribui à escola e aos estudos nesse processo. Para a execução da pesquisa foi escolhida a rede social Orkut. A comunidade escolhida apresentava membros falando de assuntos relacionados à escola onde estudaram ou trabalharam.

Felipe Camilo Mesquita Kardozo defendeu o trabalho "Confissões no Facebook: Educação e Subjetivação nas Redes Sociais”, na área de Educação Brasileira, na Universidade Federal do Ceará, 
no ano de 2013. Essa pesquisa teve como referência o fenômeno da subjetivação nas redes sociais digitais, objetivando investigar a emergência de subjetividades confessionais no Facebook.

"Jogos de (se) mostrar / dizer: o sujeito e os discursos sobre a língua inglesa na rede social Orkut", dissertação defendida em 2008, por José Adjailson Uchôa-Fernandes, na área de Estudos Linguísticos e Literários em Inglês, pela Universidade de São Paulo, apresentou como objetivo estudar duas comunidades do Orkut, que tinham como temática a língua inglesa, denominadas "eu amo inglês" e "eu odeio inglês". Buscou-se analisar os enunciados produzidos no interior dessas comunidades visando à identificação de pistas a respeito do sujeito e dos modos como ele se comunica nessas mídias, especificamente, no que se refere ao conteúdo sobre língua inglesa, seu processo de aprendizagem e possíveis relações com a língua materna.

Por fim, Daniel Bonfim da Silva defendeu em 2011, na área de Design e Arquitetura da Universidade de São Paulo, o trabalho "Redes sociais virtuais: um estudo da formação, comunicação e ação social". Essa pesquisa se origina da percepção de que nas redes sociais os usuários estabelecem uma nova forma de comunicação, em que o usuário não é apenas espectador, como acontece em outras mídias, mas transforma-se em produtor e promotor de conteúdo para esse espaço.

Outro tema que foi observado na análise das teses e dissertações faz referência ao estudo do comportamento do usuário de rede social, cuja análise é preponderante para avançarmos na discussão proposta por nossa pesquisa. Esse tema aparece em quatro trabalhos apresentados a seguir. Mario Rubens de Oliveira Carneiro defendeu a tese "Geração Y e a exposição voluntária no Facebook", em 2012, na área de Administração de Empresas da Pontifícia Universidade Católica do Rio de Janeiro. $O$ objetivo consistiu em identificar os principais fatores que corroboram para o comportamento da Geração $Y$ no Facebook, principalmente, no que se refere ao quesito exposição.

Beatriz Brandão Polivanov é autora da tese "Dinâmicas de autoapresentação em sites de redes sociais: performance, autorreflexividade e sociabilidade em cenas de música eletrônica", defendida em 2012, na área de Comunicação da Universidade Federal Fluminense de Niterói-RJ. O trabalho se constitui a partir da ideia de que as redes sociais são espaços de autoapresentação de atores sociais da vida cotidiana. Dessa forma, objetivou-se entender como atores de cenas da música eletrônica paulistana e carioca se autoapresentam no Facebook.

João Osvaldo Schiavon Matta defendeu em 2012, na área de Comunicação e Semiótica, pela Pontifícia Universidade Católica de São Paulo, a tese "Mal-estar na adolescência: jovens de agendas lotadas nas redes sociais". A proposta consistia em identificar se os adolescentes pesquisados podiam ser considerados nativos digitais com vivência profunda na internet e uso competente das redes sociais, e como esses jovens consomem esse espaço.

Bruno Brito Pereira de Souza defendeu a tese "Antecedentes e dimensões do engajamento dos usuários de redes sociais: um estudo com o Facebook", em 2012, na área de Administração, da Universidade Federal de Minas Gerais. O objetivo consistiu em mensurar o engajamento do consumidor com a rede social Facebook. Esse engajamento do consumidor foi medido como um construto reflexivo de segunda ordem formado pelas dimensões de ciclo de vida, recomendações, influências e conhecimento do consumidor.

Dois trabalhos analisados tiveram como foco de investigação a manipulação ideológica e o poder. Cláudia Dias Prioste apresentou em 2013, na Faculdade de Educação da Universidade de São Paulo a tese "O adolescente e a internet: laços e embaraços no mundo virtual". Essa tese tem origem a partir do aumento de acesso à tecnologia da informação e comunicação na contemporaneidade com o objetivo de analisar os mecanismos ideológicos de manipulação psicológica impostos pela indústria cultural à subjetividade juvenil. Dessa forma, o trabalho visou a identificar hábitos e interesses dos adolescentes no ciberespaço que pudessem influir em sua constituição subjetiva. 
"O Eu e o Outro Online: Discurso, Poder e Identidade nas Redes Sociais" de Ana Paula Melo Sylvestre, dissertação de Mestrado em Linguística, defendida pela Universidade de Brasília, em 2013, apresenta como objetivo central a investigação de como as relações discursivas evidenciam a construção de identidades nas Redes Sociais, em especial no Twitter e no Facebook. Também propõe verificar como as relações assimétricas de poder são mantidas ou modificadas nas práticas sociais nesses espaços. A facilidade para acessar um determinado discurso por meio das Redes Sociais traz importantes questões a serem investigadas, como: seriam as Redes Sociais espaços que asseguram uma forma de democratização do discurso? Relações assimétricas de poder são perceptíveis nesses espaços? As Redes Sociais podem ser recurso de manutenção do poder hegemônico? Podem ainda ser espaço para mudança social?

A revisão de literatura também nos apresentou dois trabalhos que estudaram o uso das redes sociais para o estabelecimento de laços sentimentais. Nessa linha de análise, Mariana Santiago de Matos-Silva defendeu em 2011 a tese "'Teclando' com os mortos: um estudo sobre o uso do Orkut por pessoas em luto". Esse trabalho foi desenvolvido na área de Psicologia Clínica da Pontifícia Universidade Católica do Rio de Janeiro. A internet promoveu mudanças em praticamente todas as áreas da vida humana, no entanto, dentre os vários recursos disponibilizados pela internet, destaca-se a possibilidade de se relacionar online seja para manter amizade ou até mesmo brigar com os outros. Além disso, a rede também possibilita que o usuário estude, namore, reclame de serviços públicos e privados ou até mesmo se relacione com perfis de pessoas falecidas.

Carlos Antonio da Silveira Junior defendeu em 2012, pela Universidade Estadual de Campinas, a dissertação "Ver e ser visto: a construção da vida migrante através de sites de redes sociais", produzido na área de antropologia cultural. O trabalho objetivou discutir o uso de sites de redes sociais por parte dos migrantes brasileiros, oriundos de Botelhos, Minas Gerais, residentes nos EUA. Para a execução da pesquisa, o autor fez um recorte das redes sociais, optando por estudar Orkut e Facebook, pois nesses dois ambientes, cotidianamente, eram construídos por meio de mensagens, fotografias ou comentários, a maneira como os migrantes percebem a sua vida antes, durante e até mesmo após a emigração para os EUA. Nesse contexto, surgiu o interesse em analisar como os migrantes promovem a sociabilidade, (re)significam a migração internacional utilizando, para isso, os sites de redes sociais Orkut e Facebook.

O próximo trabalho teve como foco de investigação a possibilidade de se empregar as redes sociais como mecanismo de aprendizagem coletiva. Izabel Patrícia Meister defendeu em 2012, na Universidade Presbiteriana Mackenzie, o trabalho "A tecitura do conhecimento nas redes sociais: habitat das inteligências coletivas". A pesquisa foi desenvolvida na área da Educação, Arte e História da Cultura, inserida no contexto das redes sociais e seus novos contornos no ciberespaço. O caráter complexo do objeto investigado norteou o estudo para um caminho marcado por uma perspectiva multidisciplinar dividida em três eixos norteadores, a saber, o conhecimento, a inteligência coletiva e a complexidade.

O último trabalho investigado apresenta como tema de estudo a identificação do papel das redes sociais no combate ao racismo. "Negritude em rede: discursos de identidade, conhecimento e militância - um estudo de caso da comunidade NEGROS do Orkut (2004-2001)" é a dissertação defendida por Melissa Maria de Freitas Andrade, na área de Educação da Universidade de São Paulo, em 2012. A pesquisa objetivou identificar o papel das redes sociais em produzir conhecimentos e propor iniciativas que permitissem o combate ao racismo no Brasil. $O$ estudo ainda teve a intenção de observar como os membros viam a comunidade e os conteúdos ali postados. 


\section{DISCUSSÃO}

Quanto à relação entre os trabalhos revisados e a tese proposta pelo autor desse estudo, as pesquisas aqui apresentadas se afastavam da investigação no que tangia ao fato de que parte dos estudos se centrou em grupos específicos de análise, como os adolescentes. Da mesma maneira, parte das pesquisas procurou investigar a relação entre organismos sociais, como as escolas, e o que sobre elas pensam os usuários das redes. Porém, quando os trabalhos discutem os mecanismos empregados pelos usuários para se apresentarem na rede, assim como abordam as formas como se dá a publicização, eles se aproximam do tema da tese, cujo propósito era identificar os conteúdos predominantes em postagens do Facebook, discutindo como essas postagens permitem a publicização e consequentemente a produção do espetáculo, fatores considerados chaves para se entender o lugar que a rede social Facebook ocupa na sociedade contemporânea.

Os trabalhos relacionados à discussão da produção de poder nas redes sociais, são norteadores também para o debate sobre o papel do Facebook, uma vez que um sistema virtual só assume importância no meio onde se apresenta se tiver a capacidade de gerar algum tipo de poder, portanto, ter essa noção sobre como esse poder é constituído nesse espaço é primordial para a discussão sobre o funcionamento e o uso das redes sociais.

Já os trabalhos finais, no total de seis, mostram como as redes sociais podem ser empregadas para diferentes funções no que se refere às relações interpessoais ali produzidas. Diante dessa variedade de temas presentes no espaço virtual, e a partir da constatação de que existem espaços voltados para a discussão de temas importantes dentro do contexto social vigente, esses trabalhos foram norteadores da investigação da tese que visava localizar onde se encontram no Facebook esse espaço de reação ao banal e de que forma tais páginas se diferenciam dos perfis direcionados por postagens de cunho expositivo.

\section{CONSIDERAÇÕES FINAIS}

O período de revisão de literatura apresentou que as pesquisas sobre redes sociais entre 2008 e 2014 tinha como predominância temática a construção da identidade do usuário na rede social, com a observação do conteúdo gerado por esses usuários. Porém, a revisão também evidenciou que tais pesquisas recortavam o assunto no que se refere ao tipo de publicação, dando ênfase à construção de identidades específicas e não a uma compreensão mais generalizada das personagens que transitam pelas redes sociais. Da mesma forma, os trabalhos que tiveram com foco de estudo o comportamento do usuário o espaço das redes sociais, procuram fazê-lo em situações específicas e não relacionadas a qualquer participação do sujeito no espaço virtual.

A revisão de literatura também mostrou que nesse período já existiam pesquisadores preocupados com a capacidade de manipulação ideológica das redes, assim como a geração de poder, assunto que no presente se evidencia cada vez mais nesse ambiente. Também se encontrou pesquisadores discutindo como os sentimentos pessoais são trabalhados no espaço virtual, mas tais trabalhos também tinham foco direcionado para situações específicas. Por fim, vislumbrou-se que naquele momento tinham pesquisadores direcionando suas análises para as potencialidades de comunicação do espaço, fator que gerou pesquisas sobre a maneira como as redes sociais poderiam contribuir para a geração de conhecimento e até mesmo para a luta contra as práticas racistas.

Esses trabalhos analisados evidenciaram a heterogeneidade do espaço virtual das redes sociais e o leque de opções para que novos estudos possam ser realizados na tentativa de decifrar a relação emergente que os usuários passaram a ter com essa tecnologia. Percebe-se também que tal ambiente afeta o modo de ação do sujeito que ali transita, assim abre-se uma gama de possibilidades para entender com tal ferramenta impacta a vida contemporânea. 


\section{REFERÊNCIAS}

BOYD, Danah; ELLISON, Nicole. Social network sites: definition, history, and schoolarship. Indiana: Journal of Computer-Mediated Communication, v.13, n. 1, out. 2007. Disponível em:

<http://onlinelibrary.wiley.com/doi/10.1111/j.1083-6101.2007.00393.x/full>. Acesso em: 06 fev. 2015.

CASTELLS, Manuel. A galáxia internet - reflexões sobre internet, negócios e sociedade. Tradução de Rita Espanha. Lisboa: Fundação Calouste Gulbenkian, 2001.

LÉVY, Pierre. Ciberdemocracia. São Paulo: Instituto Piaget, 2003.

RECUERO, Raquel. Redes Sociais na Internet. Porto Alegre: Sulina, 2009.

SORJ, Bernardo. Brasil@povo.com: a luta contra a desigualdade na Sociedade da Informação. Rio de Janeiro: Jorge Zahar Ed.; Brasília-DF: Unesco, 2003.

WARD, Mike. Jornalismo Online. São Paulo: Roca, 2006. 